\title{
Pterostilbene inhibits nutrient metabolism and induces apoptosis through AMPK activation in multiple myeloma cells
}

\author{
HUILING MEI $^{1,2^{*}}$, YU XIANG $^{1 *}$, HENG MEI $^{1,2}$, BIN FANG $^{1}$, QIUGUO WANG $^{1}$,

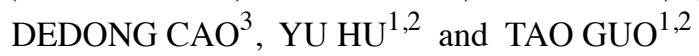 \\ ${ }^{1}$ Institute of Hematology, Union Hospital, Tongji Medical College, Huazhong University of Science and Technology;
${ }^{2}$ Collaborative Innovation Center of Hematology, Huazhong University of Science and Technology, Wuhan, Hubei 430022;
${ }^{3}$ Department of Oncology, Renmin Hospital of Wuhan University, Wuhan, Hubei 430060, P.R. China
}

Received February 6, 2018; Accepted August 13, 2018

DOI: 10.3892/ijmm.2018.3857

\begin{abstract}
Multiple myeloma (MM) cells are characterized by an abnormal nutrient metabolism that is distinct from normal plasma cells. Pterostilbene (PTE), a bioactive component of blueberries, has been demonstrated to induce apoptosis in multiple types of cancer cell. The present study evaluated whether PTE treatment affected the survival of MM cells from a metabolic perspective, and the potential mechanisms of this. It was observed that the administration of PTE induced apoptosis, which was mediated by the increased activation of AMP-activated protein kinase (AMPK). Once activated, AMPK decreased the expression and/or activity of key lipogenic enzymes, including fatty acid synthase and acetyl-CoA carboxylase. In addition, the activation of AMPK suppressed the downstream substrate, mechanistic target of rapamycin, which dephosphorylated eukaryotic initiation factor 4E-binding protein 1 , leading to a general decrease in mRNA translation. Pre-treatment with the AMPK inhibitor compound $\mathrm{C}$ prior to PTE treatment compromised the anti-myeloma apoptosis effect, suggesting the critical role of AMPK in mediating PTE-induced cell toxicity. Consistent results were obtained in vivo. Finally, autophagy was adaptively upregulated subsequent to PTE treatment; the pro-apoptotic efficacy of PTE was potentiated once autophagic flux was inhibited by 3-methyladenine. Taken together, these data demonstrated that PTE exerts anti-tumor effects on MM cells via AMPK-induced nutrient suppression.
\end{abstract}

Correspondence to: $\mathrm{Dr} \mathrm{Yu} \mathrm{Hu}$ or $\mathrm{Dr}$ Tao Guo, Institute of Hematology, Union Hospital, Tongji Medical College, Huazhong University of Science and Technology, 1,277 Jiefang Avenue, Wuhan, Hubei 430022, P.R. China

E-mail: dr_huyu@126.com

E-mail: guotao1968@163.com

${ }^{*}$ Contributed equally

Key words: multiple myeloma, pterostilbene, AMPK-activated protein kinase, nutrient metabolism, apoptosis, autophagy

\section{Introduction}

Multiple myeloma (MM) is characterized by the abnormal accumulation of clonal malignant plasma cells; it accounts for $\sim 1 \%$ of neoplastic diseases and $13 \%$ of hematological malignancies. MM is defined by the excessive production of heavy and light chain monoclonal immunoglobulins, and bone marrow plasmacytosis. It is associated with bone lesions, anemia, cytopenia, hypercalcemia, peripheral neuropathy and renal dysfunction (1). The treatment for this malignancy has advanced significantly in recent decades; however, the prognosis for patients with MM is poor despite the available chemotherapeutic agents and emerging targeted treatments (2). The relapse of MM occurs frequently, and thus, novel therapeutic modalities are required.

Pterostilbene (trans-3,5-dimethoxy-4'-hydroxystilbene; PTE) (3), predominately occurring in blueberries and certain varieties of grapes, is a naturally occurring dimethyl ether-analogue of resveratrol. However, PTE is more metabolically stable and has exhibited more favorable pharmacological activities than resveratrol as its dimethyl ether structure enhances lipophilicity and membrane permeability (4). PTE has gained significant attention for its potent antioxidant, anti-inflammatory and anticarcinogenic properties $(5,6)$. However, the mechanism of the inhibitory effect of PTE on tumor cells has not yet been completely characterized. Numerous previous research efforts have focused on the ability of PTE to target metabolic pathways that may be altered during insulin resistance or metabolic syndrome, as well as in the abnormal metabolism associated with cancer cells (7-9).

By contrast to normal human tissue, cancer cells, including MM cells, depend on a high anabolic metabolism rate. Cancer cell survival requires a high availability of de novo lipogenesis, which is achieved by overexpressing key lipogenic enzymes, including acetyl-CoA carboxylase (ACC) and fatty acid synthase (FASN) $(10,11)$. The expression of these enzymes is positively correlated with increasing cancer stage, aggressiveness and drug resistance $(12,13)$. Pharmacological inhibitors that block FASN or ACC1 activity can inhibit the survival of a range of types of cancer cells (14-16). MM cells undergo extensive protein synthesis, specifically that of immunoglobulin. Therefore, MM cells are particularly reliant on protein 
metabolism homeostasis $(17,18)$. Two opposing pathways control protein synthesis. The absence of amino acids induces the phosphorylation of $\alpha$-subunit of eukaryotic translation initiation factor-2 (eIF2 $\alpha$ ), which interferes with eIF2 and consequently hinders the initiation of translation. However, in the presence of amino acids, mechanistic target of rapamycin (mTOR) is activated and phosphorylates eIF4E-binding protein 1 (4E-BP1), which facilitates eIF4 assembly, and thus protein synthesis (19-21).

One critical monitor that may regulate cellular and organismal metabolic homeostasis is AMP-activated protein kinase (AMPK), which coordinates cell survival and apoptosis in response to nutrient and energy levels (22). AMPK is activated in response to cellular stress or pharmacological inducers that inhibit anabolic pathways. AMPK acts to decrease ATP consumption and promote catabolic pathways that generate more ATP (23). Therefore, AMPK acts as a central metabolic switch that governs metabolism. As a number of previous studies have reported the important role of AMPK in the pro-apoptotic pathway of cancer cells, AMPK is an attractive target molecule for cancer treatment $(24,25)$.

PTE is reported to mediate AMPK activation in numerous cell types, including hepatocytes and vascular endothelial cells $(26,27)$. However, the effect of PTE on the AMPK pathway in tumor cells has only been reported in prostate cancer cells (9). The effect of PTE on cancer metabolic regulation is also unclear. In the present study, the potential of PTE as a non-toxic antineoplastic strategy for patients with MM was investigated from a metabolic perspective in MM cells. It was demonstrated that PTE effectively induced MM cell apoptosis by blocking energy metabolism through the activation of AMPK. The present study suggested that targeting AMPK activation with PTE represents a relevant strategy for MM prevention and therapy.

\section{Materials and methods}

Reagents. PTE, 3-methyladenine (3-MA), monodansylcadaverine (MDC) and dimethyl sulfoxide (DMSO) were purchased from Sigma-Aldrich; Merck KGaA (Darmstadt, Germany). Compound $\mathrm{C}$ was purchased from Selleck Chemicals (Houston, TX, USA).

PTE stock solution preparation. PTE was dissolved in DMSO to yield a $78 \mathrm{mM}$ stock solution that was stored at $-20^{\circ} \mathrm{C}$. The different doses of PTE $(10,20,30,40,50,60$ and $70 \mu \mathrm{M})$ for each treatment group were diluted with RPMI-1640 medium (Sigma-Aldrich; Merck KGaA). All experiments used a corresponding volume of DMSO as a control treatment.

Cell culture. RPMI-8226, NCI-H929, U266 and ARH-77 human MM cell lines were purchased from American Type Culture Collection (Manassas, VA, USA). The RPMI-8226, NCI-H929, U266 and ARH-77 cells were cultured in RPMI-1640 medium supplemented with $10 \%$ fetal bovine serum (Gibco; Thermo Fisher Scientific, Inc., Waltham, MA, USA) and $100 \mathrm{U} / \mathrm{ml}$ penicillin/streptomycin (Beyotime Institute of Biotechnology, Haimen, China). The cells were incubated in a humidified incubator with $5 \% \mathrm{CO}_{2}$ at $37^{\circ} \mathrm{C}$.

Proliferation and viability assays. Cell viability was determined using a Cell Counting kit-8 (CCK-8; Dojindo
Laboratories, Kumamoto, Japan) assay. In brief, $1 \times 10^{4}$ cells/well were seeded into 96-well plates in a final volume of $100 \mu \mathrm{l}$ of complete culture medium with the specified concentrations of PTE. The CCK-8 reagent was added and incubated for an additional $0.5-4 \mathrm{~h}$ at $37^{\circ} \mathrm{C}$ and the optical density (OD) was measured at $450 \mathrm{~nm}$ using a microplate reader.

Western blotting. Following PTE treatment with or without $1 \mu \mathrm{M}$ compound $\mathrm{C}$ for $48 \mathrm{~h}$, the $\mathrm{MM}$ cells were harvested and lysed in radioimmunoprecipitation assay lysis solution (Beyotime Institute of Biotechnology) containing phosphatase inhibitors and PMSF. A bicinchoninic acid protein assay kit (Beyotime Institute of Biotechnology) was used to determine the protein concentrations. Protein lysates (30-50 $\mu \mathrm{g}$ per sample) were separated with 6-12\% SDS-polyacrylamide gels (Beyotime Institute of Biotechnology) and transferred to polyvinyl difluoride membranes (EMD Millipore, Billerica, MA, USA). The membranes were blocked in 5\% skimmed milk in Tris-buffered saline for $1 \mathrm{~h}$ at room temperature and incubated at $4^{\circ} \mathrm{C}$ overnight with primary antibodies against cleaved caspase 9 (Asp330; cat. no. 9501T), caspase 9 (cat. no. 9502T), poly(ADP-ribose) polymerase (PARP; cat. no. 9532), phosphorylated (p)-AMPK (Thr172; cat. no. 2535T), AMPK (cat. no. 5832T), FASN (cat. no. 3180T), ACC (cat. no. 3676T), p-ACC (Ser79; cat. no. 11818T), p-mTOR (Ser2448; cat. no. 5536), mTOR (cat. no. 2983), 4E-BP1 (cat. no. 9644T), p4E-BP1 (Thr37/46) (cat. no. 2855T), p-eIF2 $\alpha$ (Ser51; cat. no. 3398T), eIF2 $\alpha$ (cat. no. 5324T), autophagy-related (ATG)5 (cat. no. 12994T), beclin1 (cat. no. 3495T) and light chain (LC)3B (cat. no. 3868T; all dilution, 1:1,000; Cell Signaling Technology, Inc., Danvers, MA, USA), and primary antibody against cleaved caspase 3 (cat. no. ab32042; dilution, 1:500; Abcam, Cambridge, MA, USA). The primary antibody against $\beta$-actin was from Antgene (cat. no. ANT010S; dilution, 1:2,000; Wuhan, China). The membranes were incubated with horseradish peroxidase-conjugated anti-rabbit (cat. no. ANT020; dilution, 1:5,000; Antgene) or anti-mouse (cat. no. ANT019; dilution, 1:5,000; Antgene) secondary antibodies for $60 \mathrm{~min}$ at room temperature. The blots were developed using an enhanced chemiluminescence reagent (Antgene). The protein expression levels were normalized to the level of $\beta$-actin in the corresponding lanes and Image Lab 3.0 software (Bio-Rad Laboratories, Inc., Hercules, CA, USA) was used for densitometric analysis.

Flow cytometry analysis. Following PTE treatment, or PTE co-treatment with $1 \mu \mathrm{M}$ compound $\mathrm{C}$ or $3 \mathrm{mM} 3 \mathrm{MA}$, cell apoptosis was assayed with Annexin V/propidium iodide staining (PI; BD Biosciences, San Jose, CA, USA), followed by fluorescence-activated cell sorting analysis. RPMI-8226 cells were treated with $0,20,40$ or $60 \mu \mathrm{M}$ PTE and ARH-77 cells were treated with $0,10,20$ or $40 \mu \mathrm{M}$ PTE for $24 \mathrm{~h}$. Next, $1 \times 10^{6}$ cells were resuspended in $100 \mu \mathrm{l}$ Annexin V-binding buffer containing $5 \mu \mathrm{l}$ Annexin V and PI. Following incubation at room temperature for $15 \mathrm{~min}, 400 \mu \mathrm{l}$ binding buffer was added to the cells, which were analyzed using a FACSAriaII flow cytometer (BD Biosciences). The rate of apoptotic events was defined as the sum of the number of cells in the early (Annexin $\mathrm{V}^{+} / \mathrm{PI}^{-}$) and late (Annexin $\mathrm{V}^{+} / \mathrm{PI}^{+}$) stages of apoptosis. FlowJo 7.6 software (FlowJo LLC, 
Ashland, OR, USA) was used to analyze the flow cytometry data.

Visualization of autophagic vacuoles with MDC. MDC was used as an autophagolysosome-specific marker to analyze the autophagic process. Cells were seeded into 6-well plates and treated with $40 \mu \mathrm{M}$ PTE for $24 \mathrm{~h}$. Autophagic vacuoles were labeled with MDC by incubating cells with $50 \mu \mathrm{M}$ MDC at $37^{\circ} \mathrm{C}$ for $30 \mathrm{~min}$. The cells were washed with PBS three times in 5 min intervals. The cells were then immediately analyzed using a fluorescence microscope (magnification, x200; Nikon Corporation, Tokyo, Japan).

Transmission electron microscopy(TEM). The autophagosome ultrastructure of MM cells was observed by TEM. RPMI-8226 cells were exposed to $40 \mu \mathrm{M}$ PTE for 0,7 and $24 \mathrm{~h}$. The cells were fixed with $2.5 \%$ glutaraldehyde at $4^{\circ} \mathrm{C}$ for $2 \mathrm{~h}$, followed by incubation with $2 \% \mathrm{O}_{\mathrm{s}} \mathrm{O}_{4}$ for $2-3 \mathrm{~h}$ at $4^{\circ} \mathrm{C}$. Following dehydration in a graded ethanol series, cells were infiltrated and embedded in EMbed-812 (Electron Microscopy Sciences, Hatfield, PA, USA) at $60^{\circ} \mathrm{C}$ for $48 \mathrm{~h}$. Thin (60-100 nm) sections were stained at room temperature with uranyl acetate for $15 \mathrm{~min}$ and lead citrate for $10 \mathrm{~min}$, prior to being examined using a Tecnai G2 20 TWIN electron microscope (magnification, x1,700 and x5,000; FEI, Eindhoven, the Netherlands).

Animal model and treatment. A total of 10 female NOD/SCID mice (weight, 15.7 $\pm 1.0 \mathrm{~g}$; age, 3-4 weeks; Nanjing Bioscience Company, Nanjing, China) were individually maintained in a temperature-controlled $\left(23 \pm 2^{\circ} \mathrm{C}\right.$ with $50-60 \%$ relative humidity) room with a 12 -h light/dark cycle and ad libitum access to water and food. All experimental procedures and protocols were approved by the Committee on Animal Handling of Huazhong University of Science and Technology (Wuhan, China). The mice were subcutaneously injected with $2 \times 10^{7}$ RPMI-8226 cells in $200 \mu 1$ serum-free RPMI-1640 medium. The treatment began when the tumor volume reached $\sim 100 \mathrm{~mm}^{3}$ ( $\sim 3$ weeks). Tumor volumes were calculated using the following formula: $\mathrm{V}=\mathrm{AxB}^{2} / 2$, where $\mathrm{A}$ is the largest diameter and $\mathrm{B}$ the smallest. 10 mice were randomly divided into the control (5\% DMSO) or PTE (50 mg/kg in 5\% DMSO) groups $(n=5)$. Intraperitoneal injections were performed 5 days a week for 21 days. Tumor sizes were evaluated daily. All mice were sacrificed on day 21 and their tumors were excised. Tumor tissues were fixed in $10 \%$ formalin at room temperature for $24 \mathrm{~h}$ for further analysis. Blood was also collected at sacrifice and serum samples were stored at $-80^{\circ} \mathrm{C}$ until further analysis.

Terminal deoxynucleotidyl transferase mediated dUTP nick-end labeling (TUNEL) staining. A TUNEL assay kit (cat. no. 11684817910; Roche Diagnostics, Ltd., Basel, Switzerland) was used to detect apoptosis in the tumor tissues, according to the manufacturer's protocol. Tumor tissues from mice were fixed in $10 \%$ formalin at room temperature for $24 \mathrm{~h}$. Paraffin-embedded sections $(4-\mu \mathrm{m})$ from tumor tissues were deparaffinized and hydrated by sequential immersion in xylene and a graded alcohol series $(100,100,95,90,80$ and $70 \%$ ). Next, the sections were incubated with the TUNEL reaction mixture $(\mathrm{TdT}+\mathrm{dUTP}, \mathrm{v} / \mathrm{v}=1: 9)$ at $37^{\circ} \mathrm{C}$ for $1 \mathrm{~h}$, and hematoxylin was used to stain the nuclei at room temperature for $5 \mathrm{~min}$. The sections were sealed with neutral gum and visualized using a fluorescence microscope (magnification, x100; Nikon Corporation). Five fields of view for each section were observed.

Histology and immunohistochemistry (IHC). Tumors from mice were fixed in $10 \%$ formalin at room temperature for $24 \mathrm{~h}$. Paraffin-embedded sections $(4-\mu \mathrm{m})$ of tumor tissues were deparaffinized and hydrated by sequential immersion in xylene and a graded alcohol series (100, 100, 95, 90, 80 and $70 \%$ ). Following antigen retrieval with $10 \mathrm{mM}$ citrate buffer $(\mathrm{pH}=6.0)$ at $95^{\circ} \mathrm{C}$ for $10 \mathrm{~min}$, endogenous tissue peroxidase activity was blocked with $3 \%$ hydrogen peroxide at room temperature for $10 \mathrm{~min}$. Next, non-specific sites were blocked with $5 \%$ bovine serum albumin (Roche Diagnostics) at room temperature for $20 \mathrm{~min}$. The sections were incubated with antibodies against p-AMPK (Thr172; cat. no. 2535S; dilution, 1:100; Cell Signaling Technology, Inc.), p-mTOR (cat. no. bs-3494R; dilution, 1:200; Biosynthesis Biotechnology Co., Ltd., Beijing, China), FASN (cat. no. 3180S; dilution, 1:50; Cell Signaling Technology, Inc.) and cleaved caspase-3 (cat. no. RLC006; dilution, 1:50; Ruiying Biological, Suzhou, China) at $4{ }^{\circ} \mathrm{C}$ overnight. Next, the sections were incubated with the following secondary antibodies: horseradish peroxidase-conjugated anti-rabbit or anti-mouse (cat. no. K5007; dilution, 1:200; Dako; Agilent Technologies, Santa Clara, CA, USA) for $50 \mathrm{~min}$ at room temperature. The labelled cells were observed using a fluorescence microscope (Nikon Corporation) for cleaved caspase-3 (magnification, x100) and for p-AMPK, FASN and p-mTOR (magnification, x200). Five fields of view for each section were observed.

In vivo toxicity assay. Inner canthus blood samples (100 $\mu \mathrm{l})$ were collected from the mice prior to sacrifice. Blood cells were isolated by density gradient centrifugation at 3,000 x g at room temperature for $10 \mathrm{~min}$, and creatine kinase-MB (CK-MB), cardiac troponins T (cTnT), alanine aminotransferase (ALT), aspartate amino transferase (AST), alkaline phosphatase (ALP), total bilirubin (TBIL), urea nitrogen (BUN) and serum creatinine (Scr) were detected in the serum. Concentrations of CK-MB and cTnT were determined quantitatively using the commercially available CK-MB ELISA kit (cat. no. FLSW-M1025; Kehua Bio-Engineering co., Ltd., Shanghai, China) and cTnT ELISA kit (cat. no. FLSW-M763; Kehua Bio-Engineering co., Ltd.) according to the manufacturer's protocol. The absorbance at $450 \mathrm{~nm}$ was measured using an automated microplate reader. The other serum indexes, including ALT, AST, ALP, TBIL, BUN and Scr, were measured by routine methods using a fully automatic biochemical analyzer (Automatic Analyzer AU2700; Beckman Coulter, Inc., Brea, CA, USA), according to the manufacturer's protocol.

Statistical analyses. SPSS 15.0 software (SPSS Inc, Chicago, IL, USA) was used to analyze all recorded data. Data are presented as the mean \pm standard deviation of three independent experiments. Statistically significant differences between multiple group comparisons were determined using one-way analysis of variance followed by Dunnett's test. Comparisons between two groups were made using unpaired Student's 

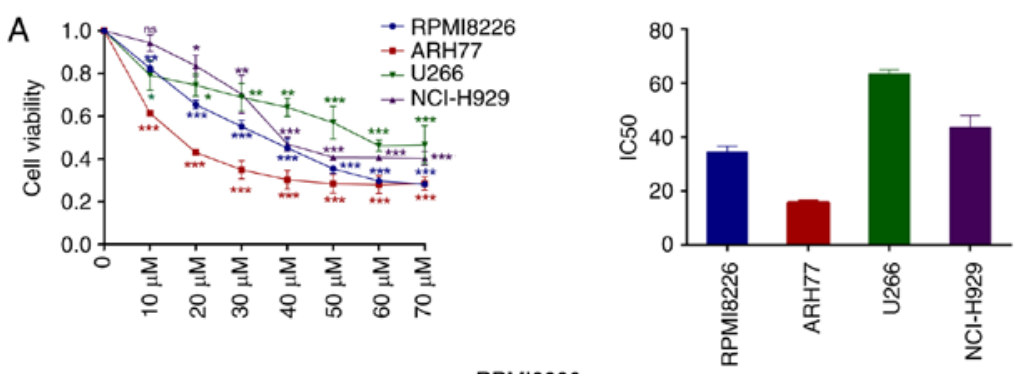

B

RPMI8226
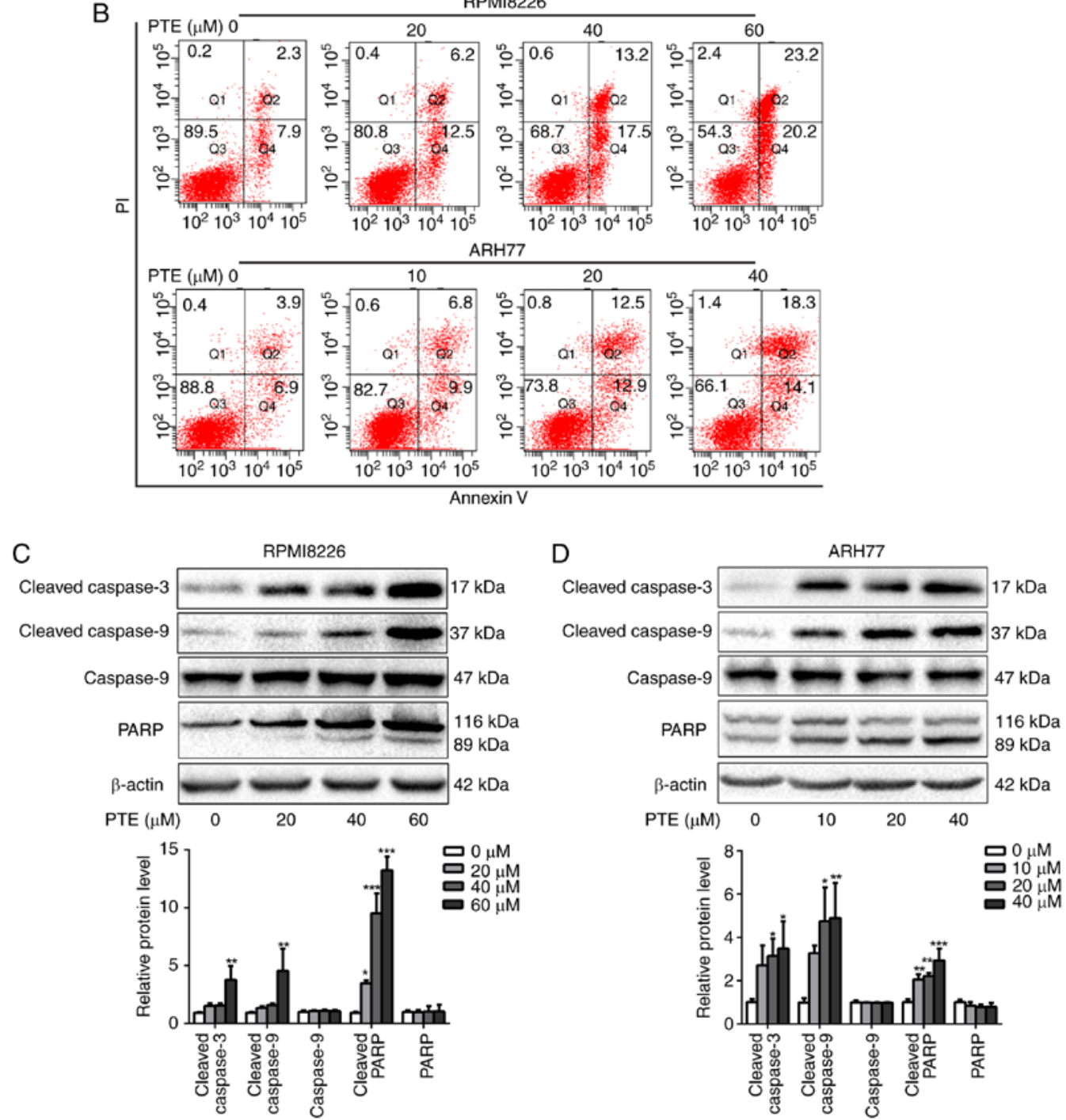

Figure 1. PTE reduces MM cell viability and induces cell apoptosis. (A) RPMI-8226, ARH-77, U266 and NCI-H929 cells were treated with PTE and their viability was measured using a Cell Counting kit- 8 assay. $\mathrm{The}^{\mathrm{IC}_{50}}$ value is shown. (B) Flow cytometric analysis of the effect of PTE on apoptosis using an Annexin V-FITC/PI kit. DMSO served as the control. (C) RPMI-8226 and (D) ARH-77 cells were treated with DMSO (control) or different concentrations of PTE for $48 \mathrm{~h}$, the expression levels of cleaved caspase 3, cleaved caspase 9 and cleaved PARP were determined using western blotting. $\beta$-actin served as a loading control. ${ }^{*} \mathrm{P}<0.05,{ }^{* *} \mathrm{P}<0.01,{ }^{* * *} \mathrm{P}<0.001$ vs. DMSO group. PTE, pterostilbene; $\mathrm{MM}$, multiple myeloma; FITC, fluorescein isothiocyanate; PI, propidium iodide; DMSO, dimethyl sulfoxide; PARP, poly(ADP-ribose) polymerase.

t-tests. $\mathrm{P}<0.05$ was considered to indicate a statistically significant difference.

\section{Results}

PTE reduces $M M$ cell viability and induces apoptosis. PTE treatment has demonstrated antitumor activity in several types of human cancer cells $(28,29)$. Therefore, the growth inhibition effect of PTE on MM cells was assessed. Different concentra- tions of PTE between 0 and $70 \mu \mathrm{M}$ were applied to the MM RPMI-8226, ARH-77, U266 and NCI-H929 cell lines for $48 \mathrm{~h}$. Consistent with other previous studies (30,31), a significant reduction in cell viability was observed following the PTE treatment of MM cells. PTE induced the concentration-dependent decrease in viability of RPMI-8226, ARH77, U266 and NCI-H929 cells, with $\mathrm{IC}_{50}$ values at $48 \mathrm{~h}$ of $33.8,16.6,63.5$ and $44.5 \mu \mathrm{M}$, respectively (Fig. 1A). The relatively sensitive RPMI-8226 and ARH-77 cells were used for subsequent experiments. 


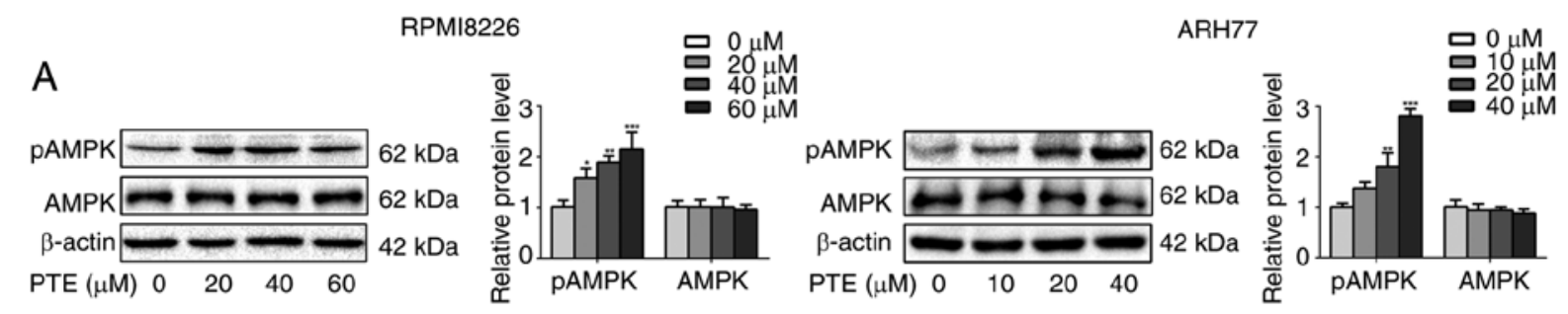

B

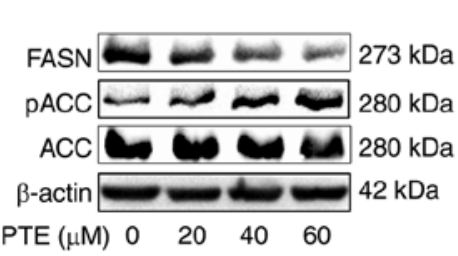

RPMI8226

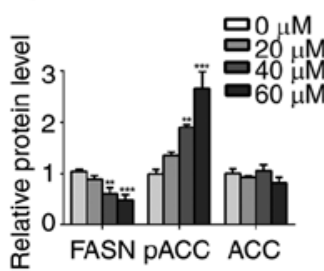

ARH77

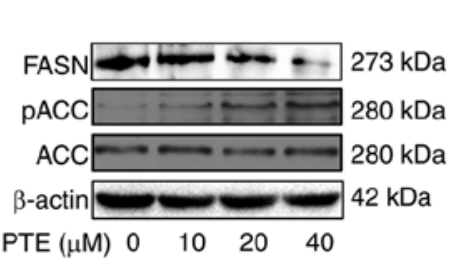

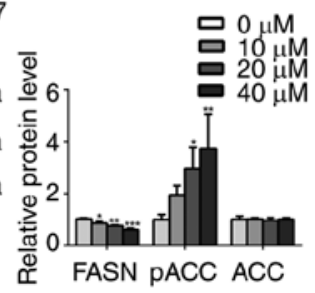

C

RPMI8226
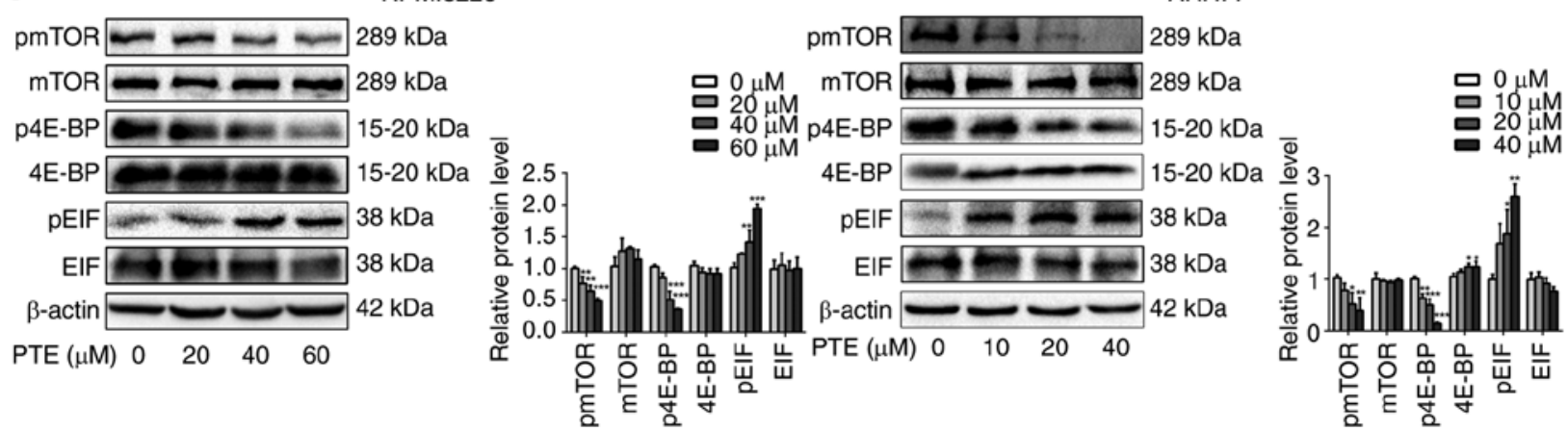

Figure 2. PTE suppresses the expression of metabolic proteins in MM cells. RPMI-8226 (left) and ARH-77 (right) cells were treated with DMSO (control) or different concentrations of PTE for $48 \mathrm{~h}$. Western blotting was used to analyze the protein expression levels of (A) p-AMPK (Thr 172); (B) FASN, p-ACC (Ser 79) and ACC; (C) p-mTOR (Ser 2448), mTOR, p-4E-BP1 (Thr 37/46), 4E-BP1, eIF2 $\alpha$ and p-eIF2 $\alpha$. $\beta$-actin served as a loading control. The presented western blotting data are representative of those obtained in at least three separate experiments. ${ }^{*} \mathrm{P}<0.05,{ }^{* *} \mathrm{P}<0.01,{ }^{* * * *} \mathrm{P}<0.001$ vs. the DMSO group. $\mathrm{PTE}$, pterostilbene; MM, multiple myeloma; DMSO, dimethyl sulfoxide; p-, phosphorylated; AMPK, AMP-activated protein kinase; FASN, fatty acid synthase; ACC, acetyl-CoA carboxylase; mTOR, mechanistic target of rapamycin; 4E-BP1, 4E-binding protein 1; eIF2 $\alpha$, eukaryotic translation initiation factor-2 $\alpha$.

To investigate the mechanisms of the growth inhibitory effect of PTE on MM cells, the effects of PTE on the rate of apoptosis were analyzed by flow cytometry. PTE treatment for $24 \mathrm{~h}$ induced early and late apoptosis to a greater extent compared with the DMSO-treated controls in RPMI-8226 and ARH-77 cells in a dose-dependent manner (Fig. 1B). Compared with the control group $(2.3+7.9 \%)$, apoptosis was increased at $24 \mathrm{~h}$ in the $20 \mu \mathrm{M}(6.2+12.5 \%), 40 \mu \mathrm{M}(13.2+17.5 \%)$ and $60 \mu \mathrm{M}(23.2+20.2 \%)$ PTE-treated groups in RPMI-8226 cells. Similar findings were observed in ARH77 cells, in which apoptosis was increased at $24 \mathrm{~h}$ in the $10 \mu \mathrm{M}(6.8+9.9 \%)$, $20 \mu \mathrm{M}(12.5+12.9 \%)$ and $40 \mu \mathrm{M}(18.3+14.1 \%)$ PTE-treated groups, compared with the control group (3.9+6.9\%). Taken together, these data indicated that PTE treatment increased the rate of apoptosis of MM cells.

These results coincided with a marked increase in the expression of the pro-apoptotic proteins, cleaved PARP and cleaved caspase 3/9, following PTE exposure for $48 \mathrm{~h}$ in RPMI-8226 and ARH-77 cells (Fig. 1C and D). Taken together, these results suggested that PTE treatment attenuates MM cell viability and induces apoptosis.

PTE treatment activates the AMPK pathway in MM cells. As the survival of MM cells depends on high rates of anabolic metabolism, and AMPK is a critical energy sensor in cellular metabolism $(23,32)$, it was assessed whether PTE treatment activated the AMPK pathway in MM cells. RPMI-8226 and ARH-77 cells were exposed to different concentrations of PTE for $48 \mathrm{~h}$, and the western blot data from these cells demonstrated that PTE induced the phosphorylation of AMPK in a dose-dependent manner (Fig. 2A).

The activity of the de novo fatty acid synthesis key enzymes FASN and ACC is negatively regulated by AMPK (33). Therefore, it was then investigated whether PTE decreased lipid synthesis by decreasing FASN expression or inhibiting ACC activity. It was observed that the FASN protein expression level was decreased, and ACC was phosphorylated in a dose-dependent manner when RPMI-8226 and ARH-77 cells were treated with PTE (Fig. 2B). The inhibition of lipogenic key enzymes may induce MM cells into a low de novo lipogenesis state.

As the survival of MM cells is dependent on extensive protein synthesis and the activation of AMPK inhibits the mTOR protein synthesis pathway $(34,35)$, it was next examined whether the activation of AMPK by PTE affected the mTOR signaling pathway. It was demonstrated that PTE treatment for $48 \mathrm{~h}$ could inhibit mTOR phosphorylation in a dose-dependent manner in RPMI-8226 and ARH-77 cells. 
A
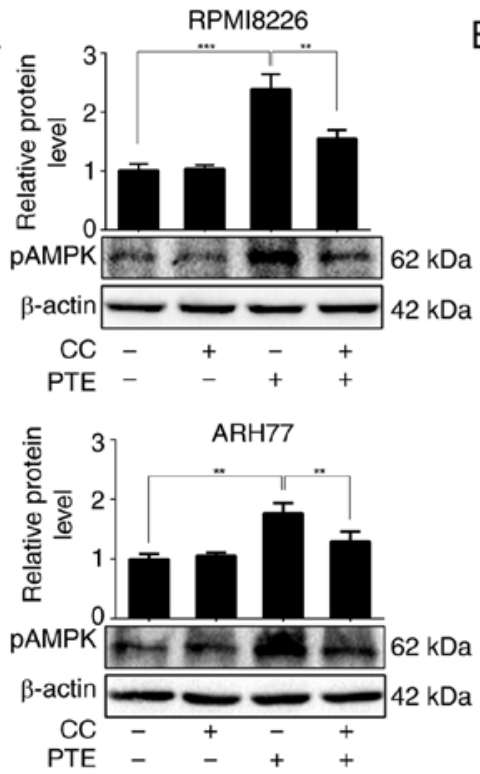

B

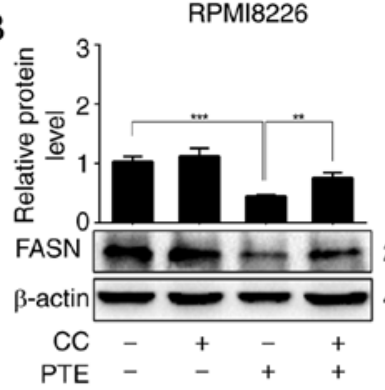

ARH77

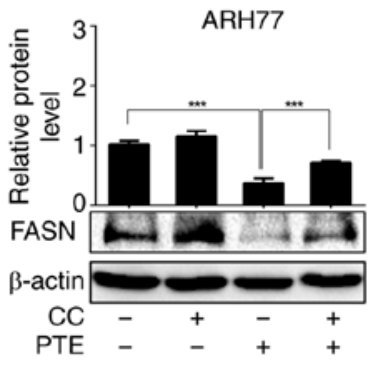

C

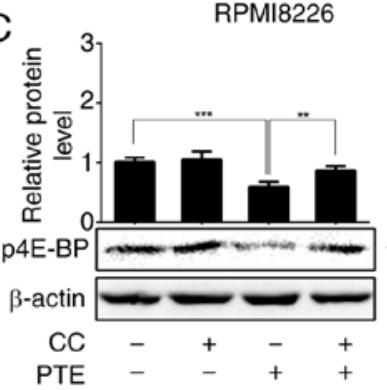

$15-20 \mathrm{kDa}$

$42 \mathrm{kDa}$

\section{RPMI8226}

D
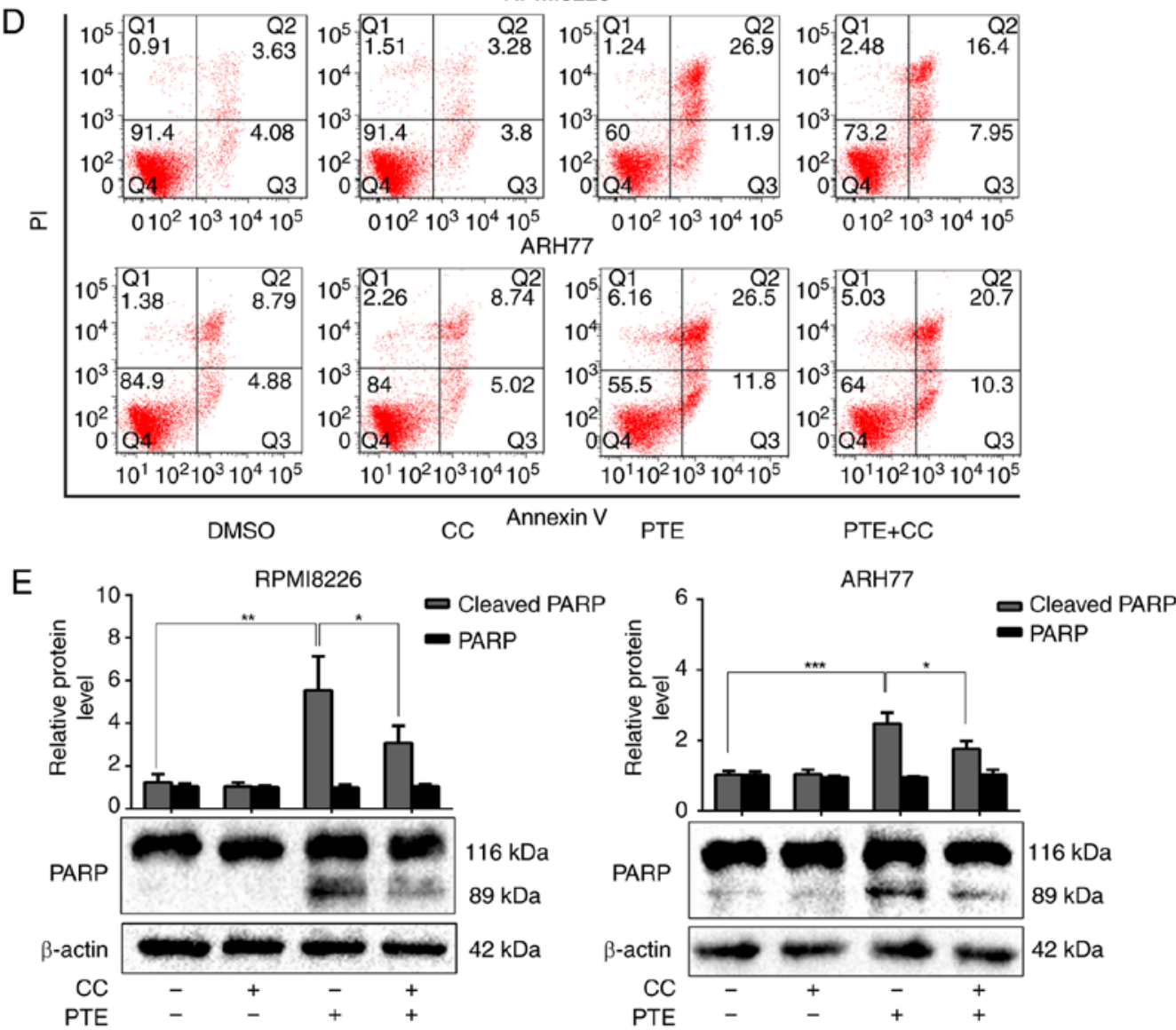

Figure 3. PTE induces MM cells apoptosis in a AMPK-dependent manner. RPMI-8226 and ARH-77 cells were treated with PTE in the absence or presence of CC. Western blotting analyzed the levels of (A) p-AMPK (Thr 172), (B) FASN and (C) p-4E-BP1. $\beta$-actin served as a loading control; (D) Flow cytometric analysis of apoptotic effects using an Annexin V-FITC/PI kit. (E) Western blot analysis of the levels of PARP. $\beta$-actin served as a loading control. "P<0.05, ${ }^{* *} \mathrm{P}<0.01,{ }^{* * *} \mathrm{P}<0.001$ vs. PTE-only group. PTE, pterostilbene; MM, multiple myeloma; AMPK, AMP-activated protein kinase; $\mathrm{CC}$, compound $\mathrm{C}$; $\mathrm{p}$, phosphorylated; FASN, fatty acid synthase; 4E-BP1, 4E-binding protein 1; FITC, fluorescein isothiocyanate; PARP, poly(ADP-ribose) polymerase.

The best understood roles of mTOR in mammalian cells are regarding the control of mRNA translation by phosphorylating 4E-BP1 (20), it was observed that the inhibition of mTOR phosphorylation was accompanied by the decreased phosphorylation of 4E-BP1. Furthermore, eIF $2 \alpha$ phosphorylation was increased in a dose-dependent manner (Fig. 2C). These results indicated that PTE activates AMPK phosphorylation to suppress the expression level and activity of lipogenesis- and mRNA translation-associated enzymes, potentially driving MM cells into a low nutrient state. 
A

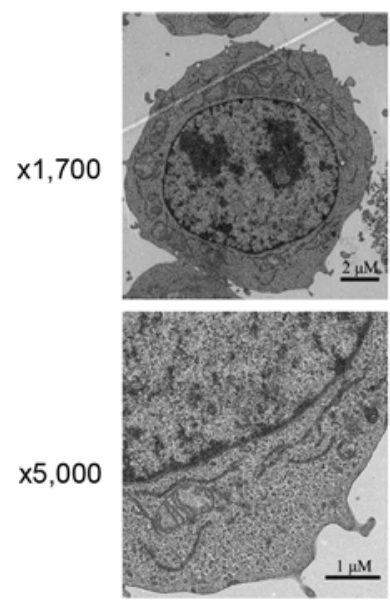

$\mathrm{Oh}$
RPMI8226
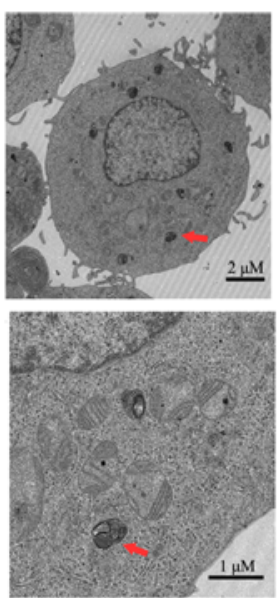

$7 \mathrm{~h}$
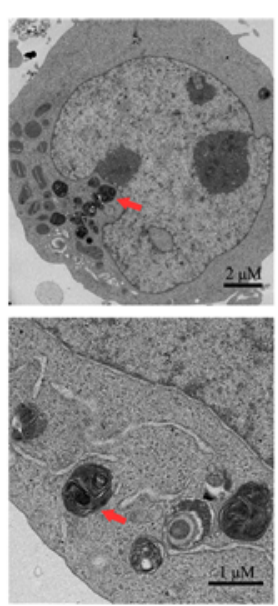

$24 \mathrm{~h}$
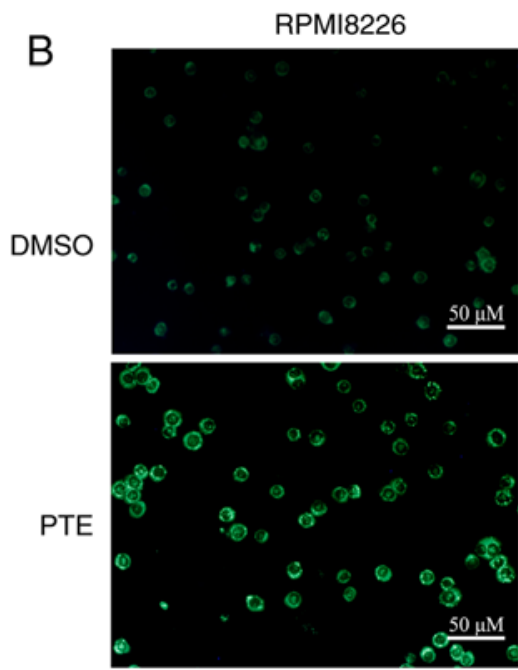

C

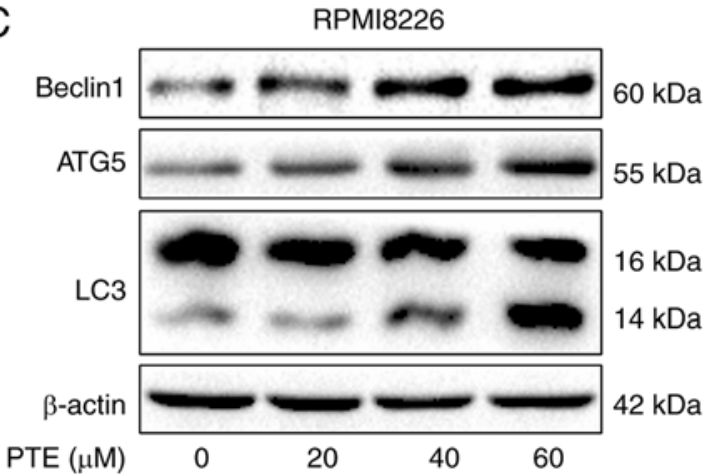

$E(\mu \mathrm{M})$

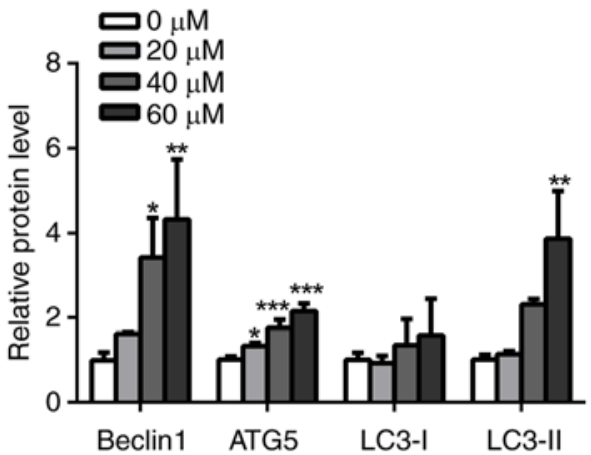

D
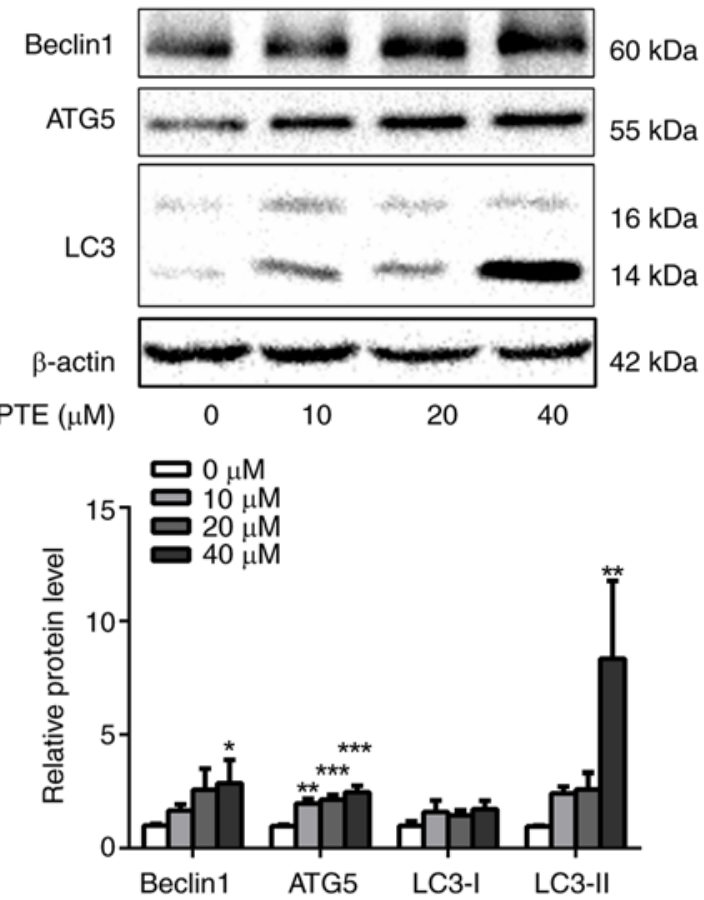

RPMI8226

E

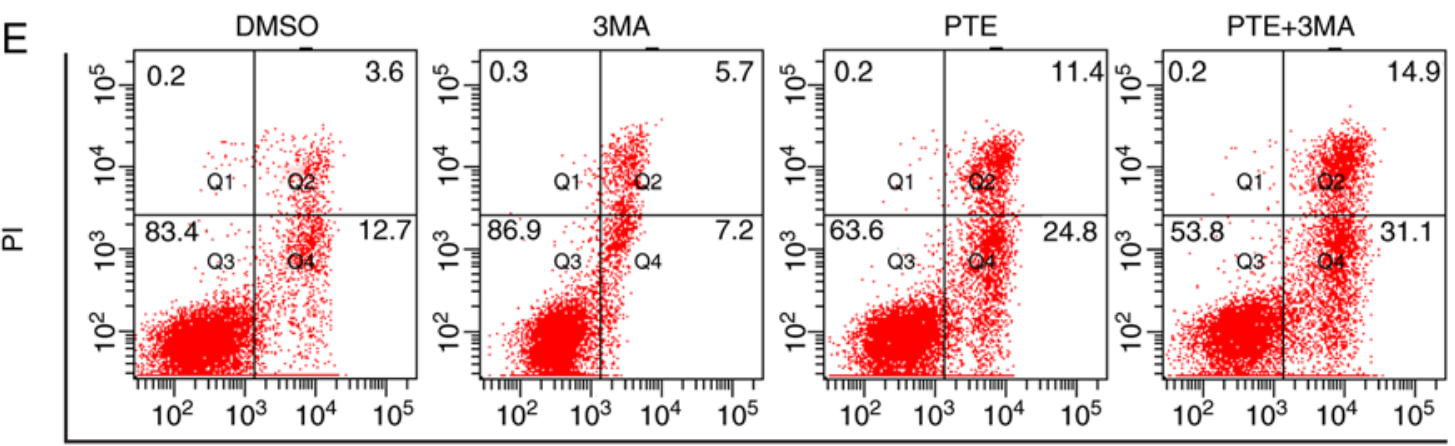

Annexin V

Figure 4. PTE treatment induces autophagy. (A) Transmission electronic microscopy analyzed the autophagy-associated morphological change in RPMI-8226 cells following exposure to PTE. Upper panel, x1,700 magnification; lower panel, x5,000 magnification. (B) Monodansylcadaverine-labeled vacuoles were observed in RPMI-8226 cells using a fluorescence microscope. (C) RPMI-8226 and (D) ARH-77 cells were treated with DMSO (control) or different concentrations of PTE for $48 \mathrm{~h}$, western blotting was applied to investigate the levels of the autophagy markers beclin1, ATG5 and LC3. $\beta$-actin was used as a loading control. (E) Effect of PTE treatment on RPMI-8226 cells with or without 3MA was analyzed by flow cytometry using an Annexin V-FITC/PI kit. ${ }^{*} \mathrm{P}<0.05,{ }^{* *} \mathrm{P}<0.01,{ }^{* * *} \mathrm{P}<0.001$ vs. DMSO group. PTE, pterostilbene; ATG5, autophagy-related 5; LC3, light chain 3; 3MA, 3-methyladenine; FITC, fluorescein isothiocyanate; PI, propidium iodide. 

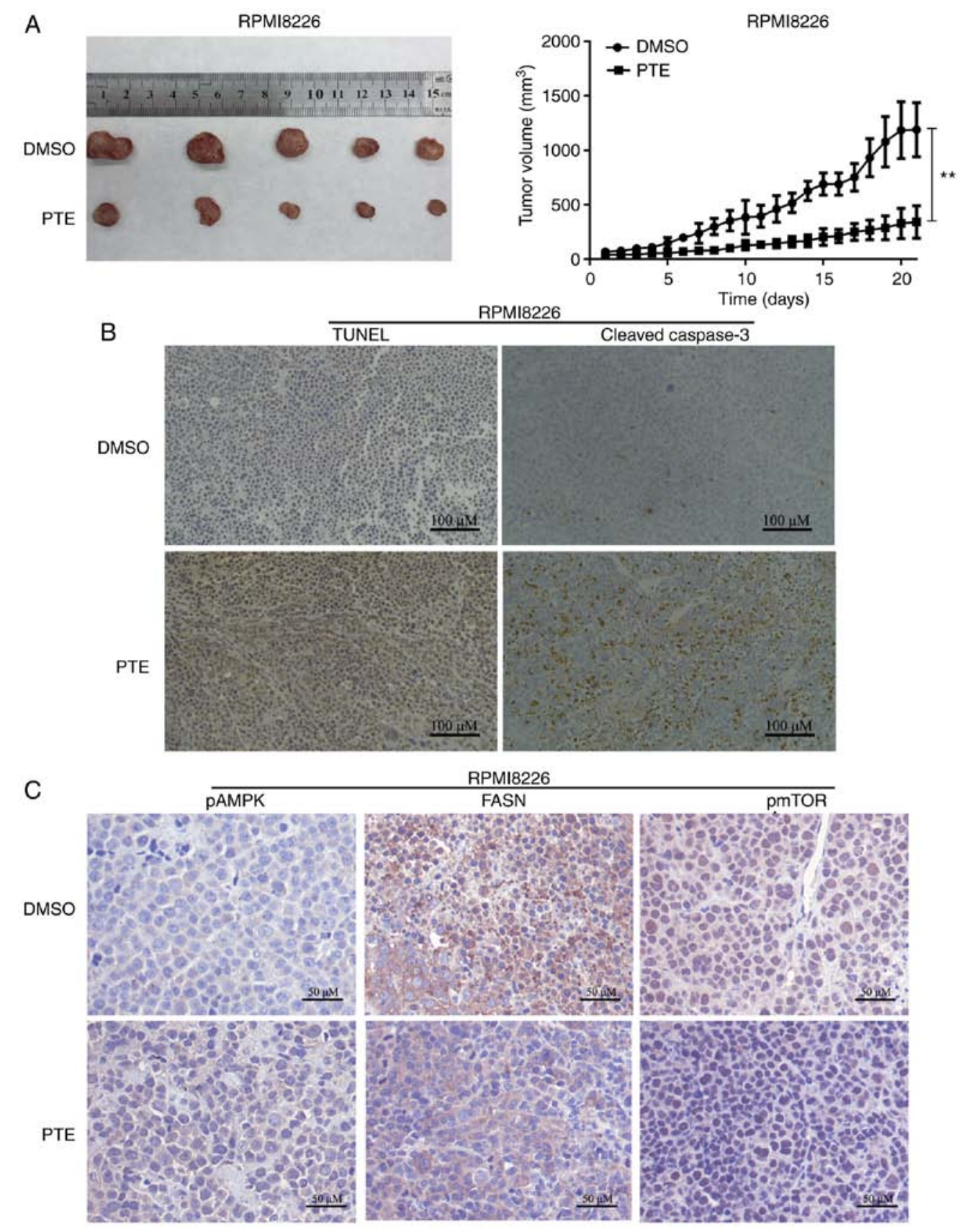

Figure 5. PTE inhibits MM progression in vivo. (A) Representative image (left) and growth curves (right) of xenograft tumors from NOD/SCID mice subcutaneously injected with RPMI-8226 cells and treated with 5\% DMSO or PTE. (B) Immunohistochemical analysis of terminal deoxynucleotidyltransferase-mediated dUTP nick-end labeling and cleaved caspase 3 on tumor tissue sections from mice injected with RPMI-8226 cells and treated with 5\% DMSO or PTE. (C) Immunohistochemical analysis of p-AMPK (Thr 172), FASN and p-mTOR (Ser 2448) on tumor tissue sections from mice injected with RPMI-8226 cells and treated with 5\% DMSO or PTE ( $\mathrm{n}=5) .{ }^{* *} \mathrm{P}<0.01$ vs. DMSO group. PTE, pterostilbene; MM, multiple myeloma; DMSO, dimethyl sulfoxide; p-, phosphorylated; AMPK, AMP-activated protein kinase; FASN, fatty acid synthase; mTOR, mechanistic target of rapamycin.

PTE-induced apoptosis is dependent on the activation of $A M P K$ in MM cells. To more definitively establish the role of AMPK in mediating the apoptosis-promoting effect of PTE, a well-established pharmacological inhibitor of AMPK activity, compound C, was utilized. RPMI-8226 cells were treated with $60 \mu \mathrm{M}$ PTE and ARH-77 cells with $40 \mu \mathrm{M}$ PTE, in the absence or presence of compound $\mathrm{C}(1 \mu \mathrm{M})$. As expected, treatment with PTE alone activated AMPK phosphorylation. In addition, the expression levels of the lipogenesis-associated key enzyme FASN were decreased, and the activation of the mRNA translation-associated 4E-BP1 was suppressed in
RPMI-8226 and ARH-77 cells after 48 h. However, the FASN expression level and 4E-BP1 activity were restored in the presence of compound $\mathrm{C}$ (Fig. 3A-C). Furthermore, pre-treating RPMI-8226 and ARH-77 cells with compound $\mathrm{C}$ for $1 \mathrm{~h}$ and then exposing the cells to PTE for $24 \mathrm{~h}$ partially reduced the ability of PTE to induce apoptosis (Fig. 3D). These results coincided with the expression of the pro-apoptotic protein, cleaved PARP. Following treatment with PTE for $48 \mathrm{~h}$, the protein expression levels of cleaved PARP were increased, which were restored by co-treatment with compound $\mathrm{C}$ (Fig. 3E). Taken together, these results demonstrated that PTE 
decreased the expression level and activity of lipogenesis- and mRNA translation-associated proteins through the activation of the AMPK pathway, and the activation of AMPK at least in part, induced MM cells apoptosis.

PTE activates autophagic processes in MM cells. Autophagy is activated when cellular energy is insufficient. The AMPK/mTOR pathway is involved in the regulation of autophagy in cancer cells $(36,37)$. Therefore, the effect of PTE on autophagy was assessed. Using TEM, the gold standard for autophagy assessment, the majority of the RPMI-8226 cells in the control group were structurally complete, whereas PTE treatment resulted in an increase in autophagosomes (Fig. 4A). MDC is a specific label for autophagic vacuoles that was used to further identify PTE-induced autophagy (38). The PTE-treated RPMI-8226 cells displayed a greater fluorescence intensity and a greater number of MDC-labeled particles compared with the untreated control group (Fig. 4B). Furthermore, the western blotting analysis of cell lysates revealed the increased accumulation of autophagy markers, including LC3-II, beclin1 and ATG5, in a dose-dependent manner at $48 \mathrm{~h}$ (Fig. 4C and D). Autophagy can serve either a pro-survival or pro-death function (39). Its role in the effect of PTE intervention on MM cells was then demonstrated. The pro-apoptotic effect of PTE was further enhanced subsequent to blocking autophagic flux by co-treatment with $3 \mathrm{mM} 3 \mathrm{MA}$ for $24 \mathrm{~h}$ (Fig. 4E), indicating that PTE-induced autophagy is a cell protective mechanism, as the inhibition of autophagy aggravated PTE-induced apoptosis. These data confirmed that PTE induced autophagy in MM cells. The co-presence of PTE and an autophagy inhibitor improved the anti-MM activity compared with PTE alone.

PTE inhibits tumor growth in vivo. The in vivo antitumor effect of PTE was then examined using a mouse model. RPMI-8226 cells were subcutaneously injected into 3 -week-old female NOD/SCID mice. As demonstrated in Fig. 5A, the xenograft tumors in the mice receiving PTE treatment exhibited a reduced tumor volume compared with the mice receiving DMSO. The tumor xenografts were harvested following the final treatment, and TUNEL assays and IHC were performed. From the in situ TUNEL assays, it was observed that tumors in mice treated with PTE had increased levels of apoptotic cells compared with control mice (Fig. 5B). IHC was performed to investigate the molecular mechanisms involved in the anti-tumorigenic effects of PTE. An increase in cleaved-caspase 3 staining confirmed the induction of apoptosis in the treatment group (Fig. 5B). Similarly, an increase in p-AMPK-positive cells and a decrease in FASN- and p-mTOR-positive cells were observed with IHC in the xenograft tumors of the PTE treatment group (Fig. 5C). The in vivo data demonstrated the promising antitumor effect of PTE for the treatment of MM, associated with metabolic dependence, implying that PTE may be an effective MM treatment.

PTE displays no evident toxicity in vivo. Mice treated with PTE exhibited no notable change in body weight, food and water intake, or activity. Chemotherapy-induced heart disease, liver dysfunction or kidney malformation are common side effects that may restrict the clinical application of certain chemotherapeutic agents. Therefore, it was assessed whether the administration of PTE to tumor-bearing mice stimulated cardiac, nephritic or hepatic toxicity. Mouse plasma was collected at sacrifice, and mouse plasma myocardial damage and liver/kidney disease markers were quantified. The results revealed that the administration of PTE did not increase liver damage markers, including ALT, AST, ALP and TBIL (Fig. 6A; P>0.05). No significant increase in the kidney dysfunction indicators in BUN and Scr was observed (Fig. 6B; P>0.05). PTE treatment also did not result in cardiac damage, as no increase in cTnT or CK-MB was observed (Fig. 6C; P>0.05). Taken together, these results indicated that PTE treatment had no evident toxic effects on the heart, liver or kidneys.

\section{Discussion}

Multiple myeloma (MM) is an aggressive type of cancer. Despite notable advances with the advent of proteasome inhibitors and immunomodulatory agents, management of MM remains challenging, and relapse of MM and disease progression is common even following achievement of complete remission $(2,40)$. Multiple studies have reported that natural products derived from plants are important sources of drugs that may offer significant treatment for the majority of cancer types, including colorectal and oral cancer $(41,42)$. Consistent with previous studies, in which it was observed that PTE inhibited MM cell viability and induced cell cycle arrest through regulating the mitogen-activated protein kinase pathway $(43,44)$, the present study demonstrated that the administration of PTE could induce MM apoptosis in vitro, and decrease tumor burden in vivo. Additionally, to the best of our knowledge, the present study was the first to report that PTE-induced MM apoptosis was metabolically dependent, via the activation of AMPK, in vitro and in vivo. This study suggested that the antitumor effect of PTE may provide a novel therapeutic option for patients with MM.

Nagao et al (45) reported that the administration of PTE through diet markedly suppressed abdominal white adipose tissue accumulation in obese rats, suggesting that PTE enhanced energy expenditure and/or suppressed lipogenesis in obese rats. Gomez-Zorita et al (7) also demonstrated that PTE decreased lipogenesis in adipose tissue, and increased fatty acid oxidation in the liver. However, the effect of PTE on the metabolic regulation of cancer has yet to be reported. Our group previously reported that the fate of MM cells can be modulated by certain metabolism-associated proteins (46-48), and that leptin, as secreted by adipocytes, can promote MM cell proliferation (49). Our group also previously observed that MM cells have an abnormal de novo lipogenesis, with the increased expression of lipogenesis genes, including FASN, stearoyl-CoA desaturase 1, and ACC, in MM cell lines and MM patient tissue, consistent with a number of other cancer cell types $(10,50)$. Therefore, we hypothesized that PTE induces MM cell apoptosis by modulating aberrant lipid metabolism. In the present study, p-AMPK was upregulated by PTE treatment in a dose-dependent manner. AMPK activation regulates signaling cascades involved in metabolic events, including lipogenic activity (35). Following PTE treatment, the activation of AMPK increased the phosphorylation of 

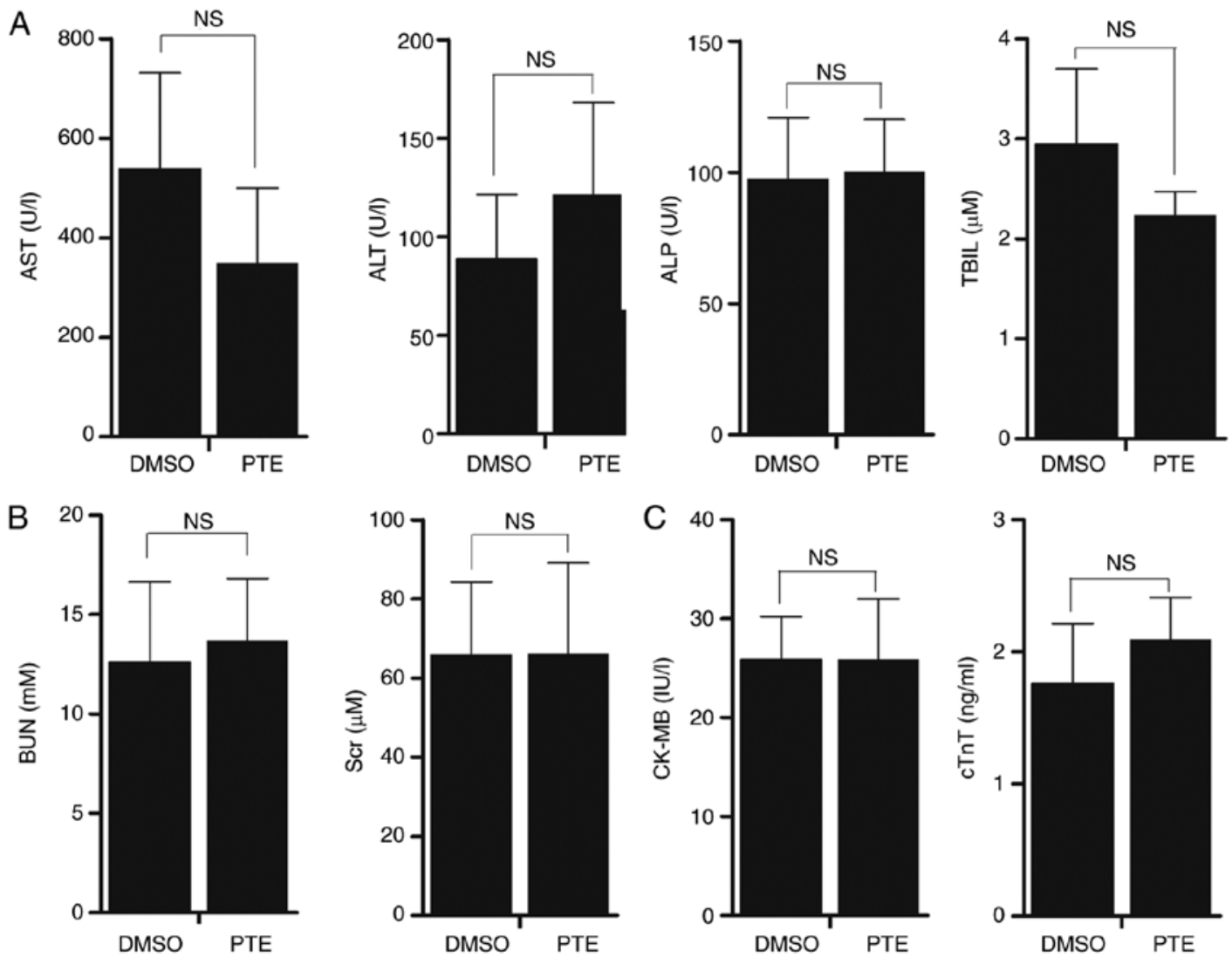

Figure 6. PTE is a safe drug for the treatment of MM. (A) Liver damage markers, including ALT, AST, ALP and TBIL were measured in serum samples from NOD/SCID mice treated with 5\% DMSO or PTE with an automatic biochemical analyzer. (B) Kidney function markers BUN and Scr were measured in serum samples from NOD/SCID mice treated with 5\% DMSO or PTE by an automatic biochemical analyzer. (C) Cardiac injury markers cTnT and CK-MB were measured with an ELISA kit. The values are expressed as means \pm standard deviation. PTE, pterostilbene; MM, multiple myeloma; ALT, alanine aminotransferase; AST, aspartate amino transferase; ALP, alkaline phosphatase; TBIL, total bilirubin; DMSO, dimethyl sulfoxide; BUN, urea nitrogen; Scr, serum creatinine; cTnT, cardiac troponins T; CK-MB, creatine kinase-MB.

ACC and decreased FASN protein expression, attenuating the expression levels/activity of these key enzymes in de novo lipogenesis.

Previous studies have highlighted the emerging role of AMPK/mTOR in cancer, and the best understood role of mTOR in mammalian cells is the control of mRNA translation through the phosphorylation of 4E-BP1 $(51,52)$. In addition to lipogenic suppression, it was observed that PTE may also act as a translation-suppressing mimetic. In the present study, it was observed that PTE treatment downregulated the phosphorylation of mTOR and, consequently, the dephosphorylation of 4E-BP1. The regulation of these key steps to translation initiation following PTE treatment may suppress general mRNA translation in MM cells. It is established that cancer cells are sensitive to nutrient shortage $(16,34)$. Once PTE treatment drives MM cells into a low-nutrient state, the cells may have been killed by the depletion of intracellular lipids and proteins. The effect of PTE on metabolic suppression and apoptosis was reversed by the pharmacological AMPK inhibitor compound $\mathrm{C}$, further confirming the central role of AMPK in mediating the nutrient suppression and antineoplastic effects of PTE on MM cells.

Autophagy occurs at physiological levels to facilitate macromolecular turnover; it is upregulated when cell homeostasis is disrupted through nutrient shortage (53). In the present study, it was observed at the molecular and cellular levels that PTE evidently induced autophagy in MM cells. It was then demonstrated that the pro-apoptotic effect of PTE was enhanced following co-treatment with autophagy inhibitors, revealing that autophagy exerts a protective role against PTE-induced apoptosis. Therefore, PTE in combination with autophagy inhibitors may be a novel alternative for the treatment of MM. As the AMPK/mTOR pathway is also involved in the regulation of autophagy in cancer cells (37), we hypothesized that treatment with PTE drives cells into a low-nutrient state, and that autophagy may be adaptively upregulated to maintain cell homeostasis through promoting the lysosomal degradation of damaged or redundant cell constituents. As a self-protective step in nutrient shortage, autophagy may promote the survival of MM cells. However, despite these observations, the underlying mechanism for the effect of autophagy on survival and apoptosis in conditions of nutrient shortage due to PTE treatment remains uncharacterized and should be the subject of further investigation.

The majority of existing treatments for MM are highly toxic. The classical chemotherapy drugs, including melphalan and cyclophosphamide, and newly emerging targeted therapy drugs are all associated with side effects, including heart, lung and liver disease. In the present study, mice treated with PTE exhibited no evident signs of toxicity based on body weight, food and water intake, activity and general examinations. Furthermore, biochemical analysis demonstrated that PTE 


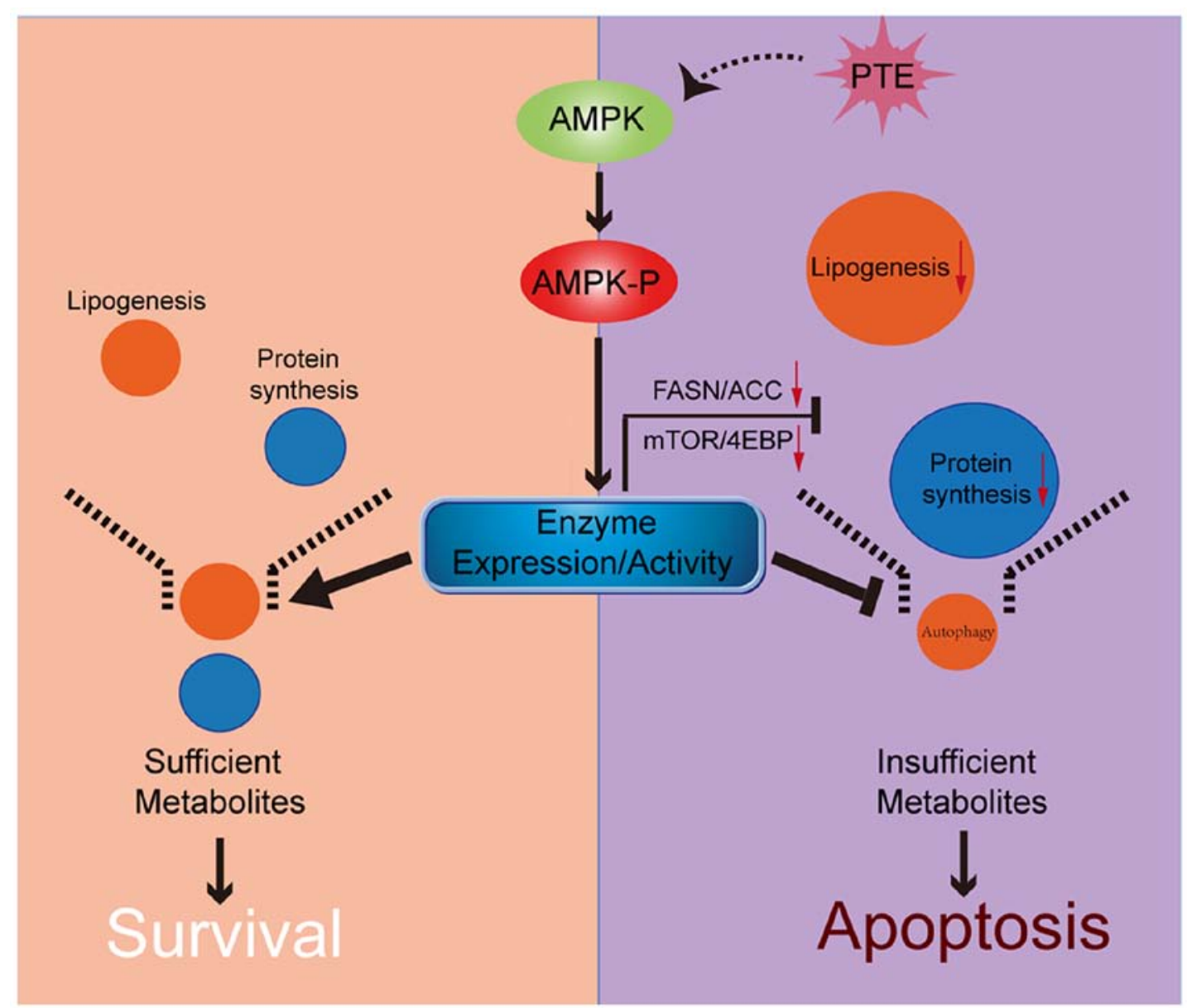

Figure 7. Schematic of the association between AMPK, nutrient metabolism, autophagy and apoptosis. PTE treatment results in the phosphorylation and thus, activation, of AMPK. Activated AMPK directly suppresses the expression levels and activity of lipogenesis and mRNA translation-related enzymes, inducing apoptosis in MM cells. Additionally, autophagy is adaptively upregulated, to protect MM cells during nutrient shortage. AMPK, AMP-activated protein kinase; PTE, pterostilbene; MM, multiple myeloma.

treatment did not induce hepatic, renal or cardiac toxicity, demonstrating that PTE is not only an effective anti-MM compound, but also a safe drug with minimal toxicity in vivo. Recent clinical trials investigating the safety of PTE concluded that it was generally safe at doses of up to $250 \mathrm{mg} /$ day in humans (54). Previous study reported that mice tolerated PTE at doses of $250 \mathrm{mg} / \mathrm{kg}$ five times per week for 21 continuous weeks presented no measurable toxicity (55). In the present study, the PTE dose used for mice was $50 \mathrm{mg} / \mathrm{kg}$, which is well within the reported safety range. This demonstrated that PTE not only possesses great anti-MM potential, but that it also may be well-tolerated and safe for patients with MM.

In recent decades, the abnormal metabolic profiles of cancer cells have been extensively studied, with the goal of identifying clinically targeted therapies. Glycolysis inhibitor, 2-deoxy-glucose, has reached phase II clinical trials (56). Statins, a class of drugs used to lower cholesterol levels, has been proven to inhibit cancer development and progression (57). Numerous data suggested that use of the standard antidiabetic agent metformin decreases cancer incidence and mortality, predominately through AMPK signal activation, including in MM cells (58). The data from the present study demonstrated that PTE could be a naturally derived AMPK activator in MM cells, thereby disrupting abnormal metabolic processes and further inducing the apoptosis of MM cells.
The effectiveness and safety of PTE indicates its potential for clinical use.

Notably, articles published in the 1990s have indicated that, although established from cells taken from a patient with a plasma cell leukemia (PCL), ARH-77 is actually an EBV-transformed B lymphoblastoid cell line $(59,60)$. However, ARH-77 cells have continued to be extensively used as a myeloma model or a PCL model over the past two decades, and has proven valuable in understanding the progression of MM, as well as for the testing of novel therapeutic strategies (61-64). Due to the controversy, attention should be paid when interpreting data from ARH-77 cells.

In conclusion, to the best of our knowledge, the present study was the first to demonstrate that PTE decreases lipid and protein synthesis through the activation of the AMPK pathway, which directly leads to the apoptosis of MM cells. Following PTE treatment, autophagy is adaptively upregulated, and co-treatment with an autophagy inhibitor may further potentiate the anti-MM efficacy of PTE (Fig. 7). Taken together, the data provided an improved understanding of the association between nutrient metabolism, autophagy and apoptosis in PTE intervention. The present study indicated that the antineoplastic activity of PTE on MM cells could provide a novel therapeutic option for patients with MM. 


\section{Acknowledgements}

The authors would like to thank the members at the Collaborative Innovation Center of Hematology, China for providing assistance with statistical analysis, and the Wuhan Institute of Virology, Chinese Academy of Sciences for providing assistance with TEM.

\section{Funding}

No funding was received.

\section{Availability of data and materials}

The datasets used and/or analyzed during the present study are available from the corresponding author on reasonable request.

\section{Authors' contributions}

TG and HuM designed the project. HuM, YX and QW performed the experiments. HuM, YX and DC analyzed the data. HuM and BF prepared all the figures. HuM, YX and BF wrote the manuscript. HM, TG and YH guided and supervised the study. All authors read and approved the final manuscript.

\section{Ethics approval and consent to participate}

The present study was approved by the Committee on Animals Handling of Huazhong University of Science and Technology (Wuhan, China).

\section{Patient consent for publication}

Not applicable.

\section{Competing interests}

The authors declare they have no competing interests.

\section{References}

1. Rajkumar SV, Dimopoulos MA, Palumbo A, Blade J Merlini G, Mateos MV, Kumar S, Hillengass J, Kastritis E, Richardson $\mathrm{P}$, et al: International myeloma working group updated criteria for the diagnosis of multiple myeloma. Lancet Oncol 15: e538-e548, 2014.

2. Dimopoulos MA, Richardson PG, Moreau P and Anderson KC: Current treatment landscape for relapsed and/or refractory multiple myeloma. Nat Rev Clin Oncol 12: 42-54, 2015.

3. Estrela JM, Ortega A, Mena S, Rodriguez ML and Asensi M: Pterostilbene: Biomedical applications. Crit Rev Clin Lab Sci 50: 65-78, 2013.

4. Wang $P$ and Sang S: Metabolism and pharmacokinetics of resveratrol and pterostilbene. Biofactors 44: 16-25, 2018.

5. Kosuru R, Rai U, Prakash S, Singh A and Singh S: Promising therapeutic potential of pterostilbene and its mechanistic insight based on preclinical evidence. Eur J Pharmacol 789: 229-243, 2016.

6. Wakimoto R, Ono M, Takeshima M, Higuchi T and Nakano S: Differential anticancer activity of pterostilbene against three subtypes of human breast cancer cells. Anticancer Res 37: 6153-6159, 2017

7. Gomez-Zorita S, Fernandez-Quintela A, Lasa A, Aguirre L, Rimando AM and Portillo MP: Pterostilbene, a dimethyl ether derivative of resveratrol, reduces fat accumulation in rats fed an obesogenic diet. J Agric Food Chem 62: 8371-8378, 2014.
8. Kosuru R and Singh S: Pterostilbene ameliorates insulin sensitivity, glycemic control and oxidative stress in fructose-fed diabetic rats. Life Sci 182: 112-121, 2017.

9. Lin VC, Tsai YC, Lin JN, Fan LL, Pan MH, Ho CT, Wu JY and Way TD: Activation of AMPK by pterostilbene suppresses lipogenesis and cell-cycle progression in p53 positive and negative human prostate cancer cells. J Agric Food Chem 60: 6399-6407, 2012.

10. Wang MD, Wu H, Fu GB, Zhang HL, Zhou X, Tang L, Dong LW, Qin CJ, Huang S, Zhao LH, et al: Acetyl-coenzyme A carboxylase alpha promotion of glucose-mediated fatty acid synthesis enhances survival of hepatocellular carcinoma in mice and patients. Hepatology 63: 1272-1286, 2016.

11. Okawa Y, Hideshima T, Ikeda H, Raje N, Vallet S, Kiziltepe T, Yasui H, Enatsu S, Pozzi S, Breitkreutz I, et al: Fatty acid synthase is a novel therapeutic target in multiple myeloma. $\mathrm{Br} \mathrm{J}$ Haematol 141: 659-671, 2008.

12. Flaveny CA, Griffett K, El-Gendy Bel D, Kazantzis M, Sengupta M, Amelio AL, Chatterjee A, Walker J, Solt LA, Kamenecka TM and Burris TP: Broad anti-tumor activity of a small molecule that selectively targets the warburg effect and lipogenesis. Cancer Cell 28: 42-56, 2015.

13. Zaytseva YY, Rychahou PG, Gulhati P, Elliott VA, Mustain WC, O'Connor K, Morris AJ, Sunkara M, Weiss HL, Lee EY and Evers BM: Inhibition of fatty acid synthase attenuates CD44-associated signaling and reduces metastasis in colorectal cancer. Cancer Res 72: 1504-1517, 2012.

14. Li L, Pilo GM, Li X, Cigliano A, Latte G, Che L, Joseph C, Mela M, Wang C, Jiang L, et al: Inactivation of fatty acid synthase impairs hepatocarcinogenesis driven by AKT in mice and humans. J Hepatol 64: 333-341, 2016.

15. Svensson RU, Parker SJ, Eichner LJ, Kolar MJ, Wallace M, Brun SN, Lombardo PS, Van Nostrand JL, Hutchins A, Vera L, et al: Inhibition of acetyl-CoA carboxylase suppresses fatty acid synthesis and tumor growth of non-small-cell lung cancer in preclinical models. Nat Med 22: 1108-1119, 2016.

16. Medina EA, Oberheu K, Polusani SR, Ortega V, Velagaleti GV and Oyajobi BO: PKA/AMPK signaling in relation to adiponectin's antiproliferative effect on multiple myeloma cells. Leukemia 28: 2080-2089, 2014.

17. Zismanov V, Attar-Schneider O, Lishner M, Heffez Aizenfeld R, Tartakover Matalon S and Drucker L: Multiple myeloma proteostasis can be targeted via translation initiation factor eIF4E. Int J Oncol 46: 860-870, 2015.

18. Agnelli L, Fabris S, Bicciato S, Basso D, Baldini L, Morabito F, Verdelli D, Todoerti K, Lambertenghi-Deliliers G, Lombardi L and Neri A: Upregulation of translational machinery and distinct genetic subgroups characterise hyperdiploidy in multiple myeloma. Br J Haematol 136: 565-573, 2007.

19. Holcik M and Sonenberg N: Translational control in stress and apoptosis. Nat Rev Mol Cell Biol 6: 318-327, 2005.

20. Moschetta M, Reale A, Marasco C, Vacca A and Carratu MR: Therapeutic targeting of the mTOR-signalling pathway in cancer: Benefits and limitations. Br J Pharmacol 171: 3801-3813, 2014.

21. Morotomi-Yano K, Oyadomari S, Akiyama H and Yano K: Nanosecond pulsed electric fields act as a novel cellular stress that induces translational suppression accompanied by eIF2alpha phosphorylation and 4E-BP1 dephosphorylation. Exp Cell Res 318: 1733-1744, 2012.

22. Mihaylova MM and Shaw RJ: The AMPK signalling pathway coordinates cell growth, autophagy and metabolism. Nat Cell Biol 13: 1016-1023, 2011.

23. Garcia D and Shaw RJ: AMPK: Mechanisms of cellular energy sensing and restoration of metabolic balance. Mol Cell 66: 789-800, 2017.

24. Duan W, Chen K, Jiang Z, Chen X, Sun L, Li J, Lei J, Xu Q, Ma J Li X, et al: Desmoplasia suppression by metformin-mediated AMPK activation inhibits pancreatic cancer progression. Cancer Lett 385: 225-233, 2017.

25. Zadra G, Photopoulos C, Tyekucheva S, Heidari P, Weng QP, Fedele G, Liu H, Scaglia N, Priolo C, Sicinska E, et al: A novel direct activator of AMPK inhibits prostate cancer growth by blocking lipogenesis. EMBO Mol Med 6: 519-538, 2014.

26. Dong GZ, Lee YI, Jeong JH, Zhao HY, Jeon R, Lee HJ and Ryu JH: Stilbenoids from rheum undulatum protect hepatocytes against oxidative stress through AMPK activation. Phytother Res 29: 1605-1609, 2015.

27. Zhang L, Cui L, Zhou G, Jing H, Guo Y and Sun W: Pterostilbene, a natural small-molecular compound, promotes cytoprotective macroautophagy in vascular endothelial cells. J Nutr Biochem 24: 903-911, 2013. 
28. Dhar S, Kumar A, Zhang L, Rimando AM, Lage JM, Lewin JR, Atfi A, Zhang X and Levenson AS: Dietary pterostilbene is a novel MTA1-targeted chemopreventive and therapeutic agent in prostate cancer. Oncotarget 7: 18469-18484, 2016.

29. McCormack DE, Mannal P, McDonald D, Tighe S, Hanson J and McFadden D: Genomic analysis of pterostilbene predicts its antiproliferative effects against pancreatic cancer in vitro and in vivo. J Gastrointest Surg 16: 1136-1143, 2012.

30. Wawszczyk J, Kapral M, Hollek A and Weglarz L: In vitro evaluation of antiproliferative and cytotoxic properties of pterostilbene against human colon cancer cells. Acta Pol Pharm 71: 1051-1055, 2014.

31. Liu Y, Wang L, Wu Y, Lv C, Li X, Cao X, Yang M, Feng D and Luo Z: Pterostilbene exerts antitumor activity against human osteosarcoma cells by inhibiting the JAK2/STAT3 signaling pathway. Toxicology 304: 120-131, 2013.

32. Maiso P, Huynh D, Moschetta M, Sacco A, Aljawai Y, Mishima Y, Asara JM, Roccaro AM, Kimmelman AC and Ghobrial IM: Metabolic signature identifies novel targets for drug resistance in multiple myeloma. Cancer Res 75: 2071-2082, 2015

33. Ma J, Duan W, Han S, Lei J, Xu Q, Chen X, Jiang Z, Nan L, $\mathrm{Li}$ J, Chen K, et al: Ginkgolic acid suppresses the development of pancreatic cancer by inhibiting pathways driving lipogenesis. Oncotarget 6: 20993-21003, 2015.

34. Fernando RC, de Carvalho F, Mazzotti DR, Evangelista AF Braga WMT, de Lourdes Chauffaille M, Leme AFP and Colleoni GWB: Multiple myeloma cell lines and primary tumors proteoma: Protein biosynthesis and immune system as potential therapeutic targets. Genes Cancer 6: 462-471, 2015.

35. Steinberg GR and Kemp BE: AMPK in health and disease. Physiol Rev 89: 1025-1078, 2009.

36. Lv S, Xu Q, Sun E, Zhang J and Wu D: Impaired cellular energy metabolism contributes to bluetongue-virus-induced autophagy. Arch Virol 161: 2807-2811, 2016

37. Jing K, Song KS, Shin S, Kim N, Jeong S, Oh HR, Park JH, Seo KS, Heo JY, Han J, et al: Docosahexaenoic acid induces autophagy through p53/AMPK/mTOR signaling and promotes apoptosis in human cancer cells harboring wild-type p53. Autophagy 7: 1348-1358, 2011

38. Wang Y, Han C, Lu L, Magliato S and Wu T: Hedgehog signaling pathway .regulates autophagy in human hepatocellular carcinoma cells. Hepatology 58: 995-1010, 2013.

39. Levy JMM, Towers CG and Thorburn A: Targeting autophagy in cancer. Nat Rev Cancer 17: 528-542, 2017.

40. Chim CS, Kumar SK, Orlowski RZ, Cook G, Richardson PG, Gertz MA, Giralt S, Mateos MV, Leleu X and Anderson KC: Management of relapsed and refractory multiple myeloma: Novel agents, antibodies, immunotherapies and beyond. Leukemia 32: 252-262, 2018

41. Yao Z, Xie F, Li M, Liang Z, Xu W, Yang J, Liu C, Li H, Zhou H and $\mathrm{Qu} \mathrm{LH}$ : Oridonin induces autophagy via inhibition of glucose metabolism in p53-mutated colorectal cancer cells. Cell Death Dis 8: e2633, 2017.

42. Chang CH, Lee CY, Lu CC, Tsai FJ, Hsu YM, Tsao JW, Juan YN, Chiu HY, Yang JS and Wang CC: Resveratrol-induced autophagy and apoptosis in cisplatin-resistant human oral cancer CAR cells: A key role of AMPK and Akt/mTOR signaling. Int J Oncol 50 : 873-882, 2017.

43. Xie B, Xu Z, Hu L, Chen G, Wei R, Yang G, Li B, Chang G, Sun $\mathrm{X}, \mathrm{Wu} \mathrm{H}$, et al: Pterostilbene inhibits human multiple myeloma cells via ERK1/2 and JNK pathway in vitro and in vivo. Int J Mol Sci 17: E1927, 2016.

44. Chen G, Xu Z, Chang G, Hou J, Hu L, Zhang Y, Yu D, Li B, Chang S, Xie Y, et al: The blueberry component pterostilbene has potent anti-myeloma activity in bortezomib-resistant cells Oncol Rep 38: 488-496, 2017.

45. Nagao K, Jinnouchi T, Kai S and Yanagita T: Pterostilbene, a dimethylated analog of resveratrol, promotes energy metabolism in obese rats. J Nutr Biochem 43: 151-155, 2017.

46. Cao D, Zhou H, Zhao J, Jin L, Yu W, Yan H, Hu Y and Guo T: PGC-1 $\alpha$ integrates glucose metabolism and angiogenesis in multiple myeloma cells by regulating VEGF and GLUT-4. Oncol Rep 31: 1205-1210, 2014.

47. Yu W, Cao D, Zhou H, Hu Y and Guo T: PGC-1 $\alpha$ is responsible for survival of multiple myeloma cells under hyperglycemia and chemotherapy. Oncol Rep 33: 2086-2092, 2015.

48. Cao D, Jin L, Zhou H, Yu W, Hu Y and Guo T: Inhibition of PGC-1 $\alpha$ after chemotherapy-mediated insult confines multiple myeloma cell survival by affecting ROS accumulation. Oncol Rep 33: 899-904, 2015
49. Yu W, Cao DD, Li QB, Mei HL, Hu Y and Guo T: Adipocytes secreted leptin is a pro-tumor factor for survival of multiple myeloma under chemotherapy. Oncotarget 7: 86075-86086, 2016.

50. Pandey PR, Xing F, Sharma S, Watabe M, Pai SK, Iiizumi-Gairani M, Fukuda K, Hirota S, Mo YY and Watabe K: Elevated lipogenesis in epithelial stem-like cell confers survival advantage in ductal carcinoma in situ of breast cancer. Oncogene 32: 5111-5122, 2013.

51. Inoki K, Kim J and Guan KL: AMPK and mTOR in cellular energy homeostasis and drug targets. Annu Rev Pharmacol Toxicol 52: 381-400, 2012.

52. Shieh JM, Chen YC, Lin YC, Lin JN, Chen WC, Chen YY, Ho CT and Way TD: Demethoxycurcumin inhibits energy metabolic and oncogenic signaling pathways through AMPK activation in triple-negative breast cancer cells. J Agric Food Chem 61: 6366-6375, 2013

53. Ravikumar B, Sarkar S, Davies JE, Futter M, Garcia-Arencibia M, Green-Thompson ZW, Jimenez-Sanchez M, Korolchuk VI, Lichtenberg M,Luo S, et al: Regulation of mammalian autophagy in physiology and pathophysiology. Physiol Rev 90: 1383-1435, 2010.

54. Riche DM, McEwen CL, Riche KD, Sherman JJ, Wofford MR, Deschamp D and Griswold M: Analysis of safety from a human clinical trial with pterostilbene. J Toxicol 2013: 463595, 2013

55. Chen RJ, Tsai SJ, Ho CT, Pan MH, Ho YS, Wu CH and Wang YJ: Chemopreventive effects of pterostilbene on urethane-induced lung carcinogenesis in mice via the inhibition of EGFR-mediated pathways and the induction of apoptosis and autophagy. J Agric Food Chem 60: 11533-11541, 2012.

56. Mohanti BK, Rath GK, Anantha N, Kannan V, Das BS, Chandramouli BA, Banerjee AK, Das S, Jena A, Ravichandran $\mathrm{R}$, et al: Improving cancer radiotherapy with 2-deoxy-D-glucose: Phase I/II clinical trials on human cerebral gliomas. Int J Radiat Oncol Biol Phys 35: 103-111, 1996.

57. Bjarnadottir O, Romero Q, Bendahl PO, Jirstrom K, Ryden L, Loman N, Uhlen M, Johannesson H, Rose C, Grabau D and Borgquist S: Targeting HMG-CoA reductase with statins in a window-of-opportunity breast cancer trial. Breast Cancer Res Treat 138: 499-508, 2013

58. Wang Y, Xu W, Yan Z, Zhao W, Mi J, Li J and Yan H: Metformin induces autophagy and G0/G1 phase cell cycle arrest in myeloma by targeting the AMPK/mTORC1 and mTORC2 pathways. J Exp Clin Cancer Res 37: 63, 2018.

59. Pellat-Deceunynk C, Amiot M, Bataille R, Van Riet I, Van Camp B, Omede P and Boccadoro M: Human myeloma cell lines as a tool for studying the biology of multiple myeloma: A reappraisal 18 years after. Blood 86: 4001-4002, 1995.

60. Drexler HG, Dirks WG and MacLeod RA: False human hematopoietic cell lines: Cross-contaminations and misinterpretations. Leukemia 13: 1601-1607, 1999.

61. Farnoushi Y, Cipok M, Kay S, Jan H, Ohana A, Naparstek E, Goldstein RS and Deutsch VR: Rapid in vivo testing of drug response in multiple myeloma made possible by xenograft to turkey embryos. Br J Cancer 105: 1708-1718, 2011.

62. Lin L, Benson DM Jr, DeAngelis S, Bakan CE, Li PK, Li C and Lin J: A small molecule, LLL12 inhibits constitutive STAT3 and IL-6-induced STAT3 signaling and exhibits potent growth suppressive activity in human multiple myeloma cells. Int J Cancer 130: 1459-1469, 2012.

63. Yan H, Wu QL, Sun CY, Ai LS, Deng J, Zhang L, Chen L, Chu ZB, Tang B, Wang K, et al: piRNA-823 contributes to tumorigenesis by regulating de novo DNA methylation and angiogenesis in multiple myeloma. Leukemia 29: 196-206, 2015.

64. Besse A, Stolze SC, Rasche L, Weinhold N, Morgan GJ, Kraus M, Bader J, Overkleeft HS, Besse L and Driessen C: Carfilzomib resistance due to $\mathrm{ABCB} 1 / \mathrm{MDR} 1$ overexpression is overcome by nelfinavir and lopinavir in multiple myeloma. Leukemia 32 : 391-401, 2018.

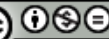

This work is licensed under a Creative Commons Attribution-NonCommercial-NoDerivatives 4.0 International (CC BY-NC-ND 4.0) License. 